\title{
Cr-Mo-V-W: a new refractory and transition metal high-entropy alloy system
}

D. Ikeuchi ${ }^{\mathrm{a},}{ }^{\dagger}$, D. J. M. King ${ }^{\mathrm{b}}$, K. J. Laws ${ }^{\mathrm{c}}$, A. J. Knowles ${ }^{\mathrm{d}}$, R. D. Aughterson ${ }^{\mathrm{e}}$, G. R. Lumpkin $^{\mathrm{e}}$, E. G. Obbard ${ }^{\mathrm{a}, \mathrm{e}^{*}}$

${ }^{a}$ School of Electrical Engineering and Telecommunications, University of New South Wales, Kensington, 2052, NSW, Australia.

${ }^{b}$ Centre for Nuclear Engineering, Imperial College London, South Kensington, London, SW7 2AZ, United Kingdom.

${ }^{c}$ School of Materials Science and Engineering, University of New South Wales, Kensington, 2052, NSW, Australia.

${ }^{d}$ Department of Materials, Imperial College London, South Kensington, London, SW7 2AZ, United Kingdom.

${ }^{e}$ Institute of Materials Engineering, Australian Nuclear Science and Technology Organisation, Lucas Heights, NSW, Australia.

${ }^{\dagger}$ Now at: School of Aerospace, Mechanical and Mechatronic Engineering, The University of Sydney, Sydney, 2006, NSW, Australia

*Corresponding Author:

E-mail:e.obbard@unsw.edu.au

Address: School of Electrical Engineering and Telecommunications, University of New South Wales, Kensington, 2052, NSW, Australia.

Telephone: +61293857625

Abstract. Cr-Mo-V-W high-entropy alloy (HEA) is studied, with $2553 \mathrm{~K}$ equilibrium solidus and high $\mathrm{Cr}$ content to promote protective oxide scale formation, suggesting potential applications in hot, oxidising environments. Alloy Search and Predict (ASAP) and phase diagram calculations found a single phase, body-centred cubic (BCC) solid solution at elevated temperatures, across the range of compositions present within the system uncommon for a HEA of refractory and transition metals. Density functional theory identified solubility of 22 at.\% $\mathrm{Cr}$ at solidus temperature, with composition-dependent drive for segregation during cooling. An as-cast, BCC single-phase with the composition 31.3Cr-23.6Mo-26.4V-18.7W exhibiting dendritic microsegregation was verified.

Keywords: Alloy Search and Predict (ASAP), refractory metals, CALPHAD, density functional theory (DFT), microstructure

Since the proposed concept of technologically relevant alloys [1-6] containing high concentrations of multiple elements in 2004 [7,8], high-entropy alloys (HEAs) have attracted increasing interest. However, many combinations of elements produce complex and brittle microstructures [9-12]. Historically, when HEAs are made from both transition and refractory metals, intermetallic phases are formed. The most common examples of this are in the Al-Co-Cr-Fe-Ni-(Ti, 
$\mathrm{Zr}$ ) systems [13-21]. This is expected as $\mathrm{Zr}$ and $\mathrm{Ti}$ form strong intermetallic compounds with many transition metals [13,22-26]. To avoid such pitfalls, predictive parameters based on the HumeRothery rules were developed $[12,27,28]$. The application of these parameters is limited as they cannot discern between mixtures that will produce a single phase solid solution or a multiphase mixture of solid solution and intermetallics, where each of these will display vastly different properties.

King et al. have developed a new method to account for the formation of intermetallic phase and to predict compositions that can form a single phase high-entropy alloy (SPHEA) [29]. Miedema's model [30] was properly utilised to calculate the enthalpies of mixing, $H_{m i x}$, of the solid solution phase and to rapidly compute $H_{m i x}$ for each possible binary intermetallic of the system. The present work applies the Alloy Search and Predict (ASAP) method to the design of an oxidationresistant refractory HEA based on three selection criteria, which are (1) to maximise melting temperature, (2) include $\mathrm{Cr}$ as an alloy component and (3) have a single phase field below the solidus. This alloy design process resulted in the combination of $\mathrm{Cr}$, Mo, $\mathrm{V}$ and $\mathrm{W}$, which is further investigated both theoretically, by the DFT and CALPHAD method, and experimentally by arcmelting. The significance of this new alloy is two-fold: (1) there are few existing SPHEAs that combine both refractory and transition elements and (2) there is significant interest in including oxide scale formers such as $\mathrm{Cr}, \mathrm{Al}$ and $\mathrm{Si}$ in refractory alloys for high strength, high temperature and oxide resistant components [31-40].

To satisfy the criteria of SPHEA, there must be a temperature below the solidus at which a single, disordered solid solution is the only phase. The ability for various metallic mixtures to form a single phase solid solution was assessed using a semi-empirical, high-throughput method of alloy prediction implemented in the ASAP software (www.alloyasap.com) [41,42]. The $\Phi$ parameter is defined as,

$$
\Phi=\frac{\Delta G_{s s}}{-\left|\Delta G_{\max }\right|}
$$


Where $\Delta G_{s s}$ is the Gibbs free energy of a solid solution of the hypothetical mixture and $\left|\Delta G_{\max }\right|$ is the maximum magnitude of the Gibbs free energy of a potential binary intermetallic compound that can form from the constituents, scaled to the number of elements in the solid solution. A commonly used parameter for assessing the deviation in atomic radii, $\delta$, between the constituents [43] is coupled with $\Phi$ whereby for a mixture that has both $\Phi \geq 1$ and $\delta \leq 6.6$, it is predicted that a SPHEA could form below the melting temperature.

Ranking the refractories by melting temperature, $\mathrm{W}$ is followed by Re, Os then Ta and Mo. If Re and Os are initially avoided based on their high cost (though they may enter singly in the following element search) and $\mathrm{Cr}$ is included as the oxide scale former, the four-component equiatomic mixtures of CrMoW- $X$ and CrTaW- $X$ are searched by ASAP for SPHEAs where $X$ was substituted by 52 elements from the periodic table.

Table 1 lists the top 10 of all four element SPHEAs $(\Phi>1$ and $\delta \leq 6.6)$ that contain CrMoW or CrTaW as predicted by the ASAP method, ranked in order of stability, $\Phi$.

Table 1. All of the predicted refractory equiatomic SPHEAs containing CrMoW or CrTaW, as predicted by the ASAP method, and their respective $\Phi$ (stability), $\delta$ (atomic radii deviation), VEC (valence electron concentration), $H_{\max (\mathrm{A}-\mathrm{B})}$ (binary with most unfavourable enthalpy of mixing), $H^{P}{ }_{\operatorname{mix}}$ (enthalpy of mixing of likely precipitate) and $H^{S S}$ mix (enthalpy of mixing of solid solution phase), $T_{p}$ (precipitate temperature) and $T_{m}$ (melting temperature) determined using experimental values of the pure elements in a weighted sum.

\begin{tabular}{lcccccccc}
\hline System & $\Phi$ & $\delta$ & VEC & $H_{\max (\mathrm{A}-\mathrm{B})}$ & $\begin{array}{c}H^{P}{ }_{\text {mix }} \\
(\mathrm{kJ} / \mathrm{mol})\end{array}$ & $\begin{array}{c}H^{S S}{ }_{\operatorname{mix}} \\
(\mathrm{kJ} / \mathrm{mol})\end{array}$ & $T_{p}(\mathrm{~K})$ & $T_{m}(\mathrm{~K})$ \\
\hline CrMoWV & 4.95 & 3.35 & 5.75 & $\mathrm{Cr}-\mathrm{V}$ & -3.07 & 1.01 & 620 & 2721 \\
CrMoWFe & 4.01 & 4.54 & 6.50 & Fe-Mo & -2.82 & 7.72 & 1159 & 2632 \\
CrMoWRe & 1.69 & 3.35 & 6.25 & Mo-Re & -10.03 & 1.13 & 1838 & 3044 \\
CrMoWCo & 1.67 & 4.78 & 6.75 & Co-Mo & -7.30 & 5.83 & 1773 & 2622 \\
CrMoWTa & 1.57 & 4.67 & 5.75 & Ta-W & -10.86 & 0.42 & 1922 & 3004 \\
CrTaWTi & 1.51 & 5.42 & 5.25 & Ta-W & -10.86 & -0.94 & 1804 & 2766 \\
CrTaWV & 1.51 & 4.83 & 5.50 & Ta-W & -10.86 & -0.27 & 1862 & 2820 \\
CrTaWNb & 1.44 & 5.27 & 5.50 & Nb-W & -12.36 & -1.47 & 2017 & 2965 \\
CrMoWTi & 1.40 & 4.89 & 5.50 & Cr-Ti & -10.85 & 0.25 & 1905 & 2667 \\
CrMoWNb & 1.36 & 4.67 & 5.75 & Nb-W & -10.85 & 0.25 & 1905 & 2667 \\
\hline
\end{tabular}


Recently, Tian et al. [44] theoretically investigated CrMoW, CrMoWMn, CrMoWCo and CrMoWNi, recognising their potential as SPHEAs. Here, V and Fe containing SPHEA compositions based on CrMoW are predicted to be markedly more stable than any others due to the relatively small enthalpies of mixing between the potential binary intermetallics, $H_{m i x}$.

Caution must be used when using ASAP to predict the lower temperature behaviour as the complete solid solution phase is only compared to intermetallic formation energies and other segregation phenomena are not explicitly considered. In the case of the CrMoVW system, the ASAP method predicts the formation of $\mathrm{CrV}$ intermetallic at $620 \mathrm{~K}$. However, there are no obvious binary intermetallics between these elements. By analysis of the binary alloy interactions, it is more likely segregation will occur into a $\mathrm{Cr}-\mathrm{V}$ rich/poor multiphase microstructure at some temperature. Fundamentally, this is due to the negative (exothermic) enthalpy of mixing between $\mathrm{Cr}-\mathrm{V}$ and positive (endothermic) enthalpy of mixing of $\mathrm{Cr}-\mathrm{W}$ and Cr-Mo. Indeed, in the binary phase diagrams, spinodal reactions exist between Cr-W [45] and Cr-Mo [46] at lower temperatures. In both cases single-phase BCC solid solutions exist at intermediate-higher temperatures. Through the addition of mutually soluble $\mathrm{V}$ and increased entropy of the multicomponent alloy, the stable temperature range of this single-phase field is expected to increase. In terms of refractory performance, our ASAP selection strategy indicates that this constitutes the highest possible melting point, Cr-containing, practical refractory SPHEA system available. Any other Cr-containing refractories have significantly lower $\Phi$, higher $\delta$ and/or reduced melting point.

Typically, most SPHEAs are temperature stabilised and will precipitate when annealed at lower temperatures $(823-1473 \mathrm{~K})$ [2,47-53]. The SPHEA phase field should also exist below the solidus for non-equilibrium solidification. For better insight into the lower temperature behaviour CALPHAD and DFT are used. The CALPHAD method is becoming increasingly effective for the study of HEAs [54-57]. A sufficiently large database now exists for the reliable calculation of phase diagrams relating to the Al-Co-Cr-Cu-Fe-Ni HEA systems [58]. From 38 metallic elements, 4495 
unique ternary combinations can be made; of these systems, 135 are fully assessed and 308 tentatively assessed [56].

The largest unknowns in both the ASAP and CALPHAD models are the enthalpies of mixing of the solid solution phases. It has been shown recently that the drive for segregation or precipitation can be due to the increased stability of the solid solution after the removal of specific species [59], not by the energetic drive of the formation of the new phase itself. This effect is difficult to capture when the enthalpy of mixing of the multicomponent solid solution phase is estimated from lower order binary and ternary systems as is done in CALPHAD and ASAP. Density functional theory was used to provide a more accurate method by explicitly calculating the enthalpy of mixing of the solid solution phases of the equiatomic binaries, ternaries and quaternary of the Cr-Mo-V-W system. Configurational contributions to the entropy were also included for the calculation of the Gibbs free energy.

Fabrication of refractory and transition metal mixtures is challenging due to the disparity in melting temperatures. The melting point of $\mathrm{W}(3683 \mathrm{~K})$ surpasses the boiling temperature of all of the transition metals [60,61]. While the ASAP-predicted melting point, $T_{m}$, of MoVW is $2918 \mathrm{~K}$ (the weighted sum of all components), the boiling point of $\mathrm{Cr}$ is $2945 \mathrm{~K}$. It is therefore in theory possible to combine $\mathrm{Cr}$ with the preceding ternary melt without complete $\mathrm{Cr}$ vaporisation. The very small margin for superheat is another reason for our stating that CrMoVW will be the highest melting point, cast refractory SPHEA containing Cr.

HEA v2.1 database "TCHEA2" as implemented by Thermocalc ${ }^{\mathrm{TM}}$ was used to produce a Cr-Mo$\mathrm{V}-\mathrm{W}$ equilibrium phase diagram. Also in Thermocalc ${ }^{\mathrm{TM}}$, the solidus temperature for non-equilibrium solidification of the CrMoVW equiatomic mixture was calculated using the Scheil model. We then proceeded to a DFT based evaluation, followed by fabrication and characterisation of an arc-melted sample. Further theoretical and experimental methodology can be found in the supplementary material. 


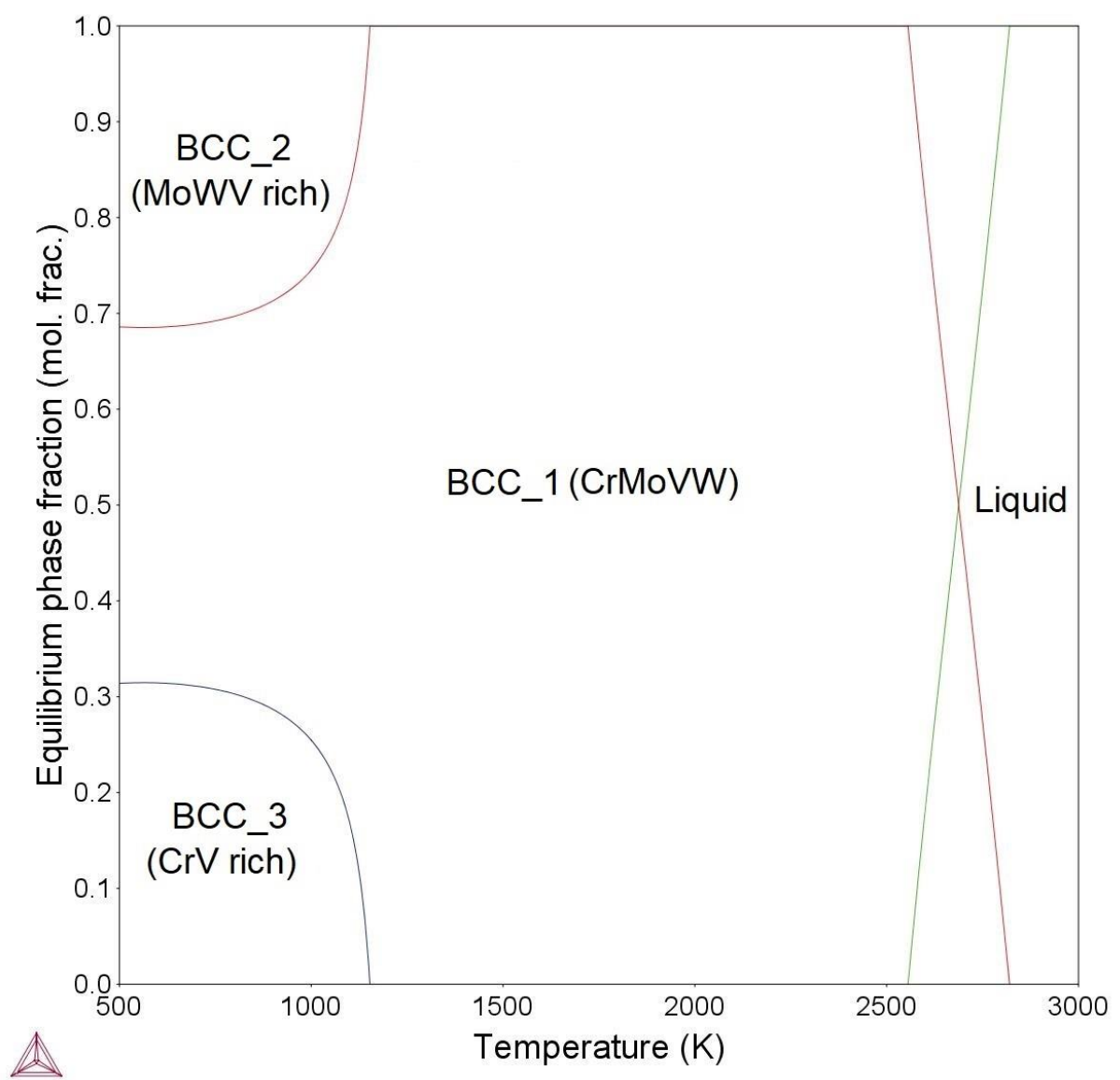

Fig. 1. Equilibrium phase diagram for CrMoVW as calculated by Thermocalc ${ }^{\mathrm{TM}}$.

The CALPHAD-predicted equilibrium and nonequilibrium solidus temperatures for equiatomic CrMoVW are $2553 \mathrm{~K}$ and $2190 \mathrm{~K}$. Figure 1 shows the calculated phase diagram. In agreement with the ASAP method, a SPHEA phase of equiatomic CrMoVW forms below the solidus with decomposition into a MoVW- and CrV-rich dual phase structure at lower temperatures. The predicted composition of these 'BCC_2 and 'BCC_3' phases at $1000 \mathrm{~K}$ are respectively $12.4 \mathrm{Cr}$ 31.1Mo-24.7V-31.8W and 61.9Cr-7.2Mo-25.9V-5.0W (at. \%). The CALPHAD predicted solidus is $531 \mathrm{~K}$ lower than $T_{m}$ predicted by ASAP. The ASAP method does not consider partial melting or the Gibbs free energy of off-stoichiometry solid solution phases. Therefore, it is expected for the two theories to deviate in predictions of this nature. 
Figure $2 \mathrm{a}$ depicts the relative stability of possible equiatomic phases between 0 and $2700 \mathrm{~K}$, calculated by DFT. Among these phases, the lowest-free-energy system will be a combination of CrMoVW and MoVW + Cr. An equimolar quaternary solid solution of CrMoVW is not the most energetically favourable phase below the solidus. Despite the increased configurational entropy of the quaternary over ternary systems, the mixing of $\mathrm{Cr}$ with MoVW increases the enthalpy of mixing (destabilises) the solid solution sufficiently for it to be energetically unfavourable relative to a dual phase of MoVW $+\mathrm{Cr}$. Figure $2 \mathrm{~b}$ shows further calculations to assess the solubility of $\mathrm{Cr}$ in the $\mathrm{Cr}_{\mathrm{x}} \mathrm{MoVW}$ solid solution.

Although the enthalpy of mixing of the quaternary solid solution increases as $x$ increases, it is predicted that the increased configurational entropy of the quaternary phase will allow for more $\mathrm{Cr}$ to be dissolved at high temperatures. Thus, $\mathrm{Cr}$ is predicted to be soluble in an equimolar MoVW ternary up to $\sim 22$ at. $\%$ at the nonequilibrium solidus temperature of $2190 \mathrm{~K}$ with a rapid drop off to $\sim 2$ at. $\%$ at room temperature. While these calculations assumed that $\mathrm{Cr}$ will segregate into a pure $\mathrm{BCC} \mathrm{Cr}$ phase, it is possible that $\mathrm{Cr}$ will segregate into a $\mathrm{Cr}-\mathrm{V}$ phase (as predicted by ASAP and CALPHAD) or may form an oxide as seen in the CrCoFeNi HEA [4,65]. Importantly, CrMoVW is identified by ASAP and CALPHAD as a potential SPHEA phase over a wide temperature range, from 1200 to $2190 \mathrm{~K}$. 

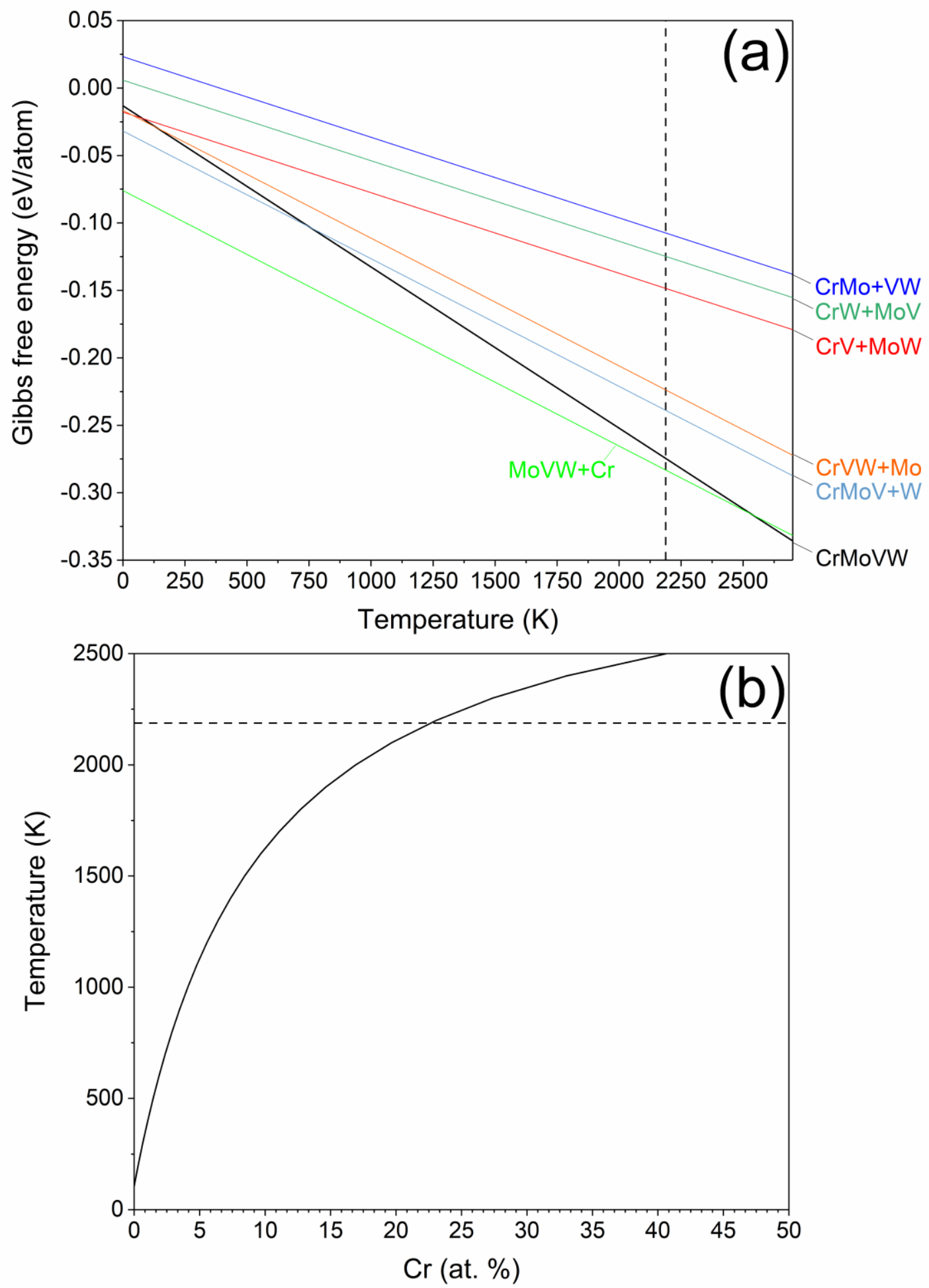

Fig. 2a. The Gibbs free energy of solid solution phases: CrMoVW (black), $\mathrm{CrV}+\mathrm{MoW}$ (red), $\mathrm{CrMo}-\mathrm{VW}$ (dark blue), $\mathrm{CrW}+\mathrm{MoV}$ (dark green), MoVW+Cr (light green), $\mathrm{CrVW}+\mathrm{Mo}$ (orange) and $\mathrm{CrVW}+\mathrm{W}$ (light blue). b. The $\mathrm{Cr}$ content in $\mathrm{Cr}_{x} \mathrm{MoVW}$ at which the Gibbs free energy will be equal to that of $\mathrm{MoVW}+\mathrm{Cr}$ (solid line) with the solidus predicted from Thermocalc represented by a dashed line. 
During melting, Cr partially vaporised due to its relatively low boiling temperature, in common with observations in past refractory HEA work $[38,66,67]$. Further, complete melting of W was not achieved. From SEM/EDS, the sample consists of three distinct regions: pure W, Mo-V-W ternary and Cr-Mo-V-W quaternary, as shown in Fig. 3a. The EDS-measured compositions are summarised in

Table 2.
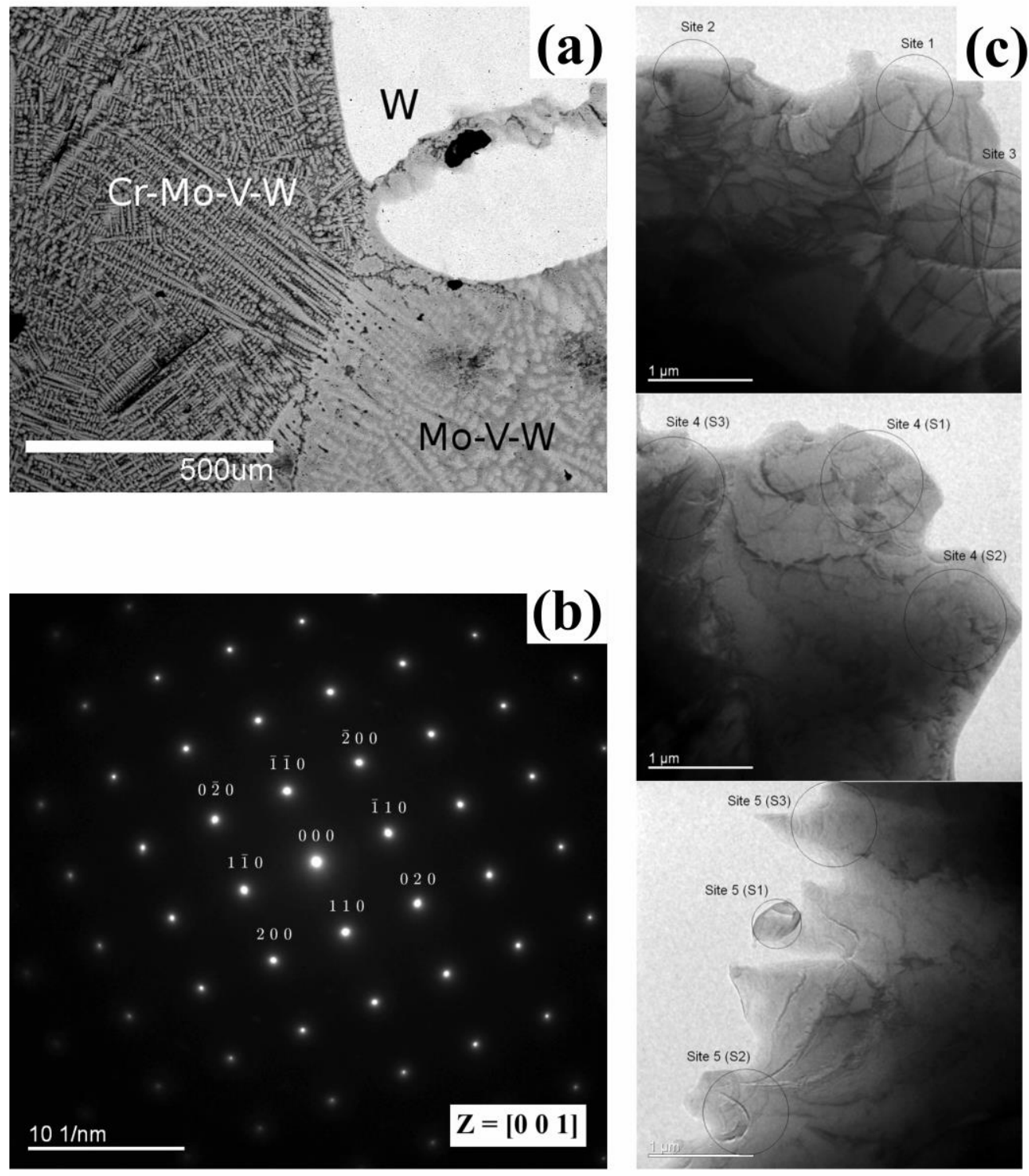

Fig. 3. (a) Scanning Electron Microscope back-scattering electron image of the as-cast CrMoVW alloy, where compositions of the labelled W, Mo-V-W and Cr-Mo-V-W regions are listed in Table 2; (b) selected Area Electron Diffraction pattern of the as-cast CrMoVW on the zone axis of [ [ $\left.\begin{array}{lll}0 & 0 & 1\end{array}\right]$ showing BCC crystal structure; (c) Transmission Electron Microscopy images of Cr-Mo-V-W material: site $1-4$ in dendritic regions, site 5 interdendritic. 
In the Mo-V-W and Cr-Mo-V-W regions the microstructure is dendritic. The bright dendrites are rich in the high atomic number higher melting temperature elements Mo and $\mathrm{W}$, while the darker interdendritic regions are rich in the lower melting temperature $\mathrm{Cr}$ and $\mathrm{V}$. The dendritic microstructure of each region occurs due to the inhomogeneous solidification above the solidus. Considering the order of melting constituent elements (which was $\mathrm{W}, \mathrm{V}, \mathrm{Mo}, \mathrm{Cr}$ - see supplementary materials) the $\mathrm{Cr}$ Mo-V-W region would have formed last due to partial melting of the Mo-V-W phase with $\mathrm{Cr}$, the last element added. This is reinforced by the orientation correlation at the interface between the regions and some liquation melting in the nearby interdendritic region.

Table 2. Chemical compositions in at. \% of the CrMoVW HEA in its as-cast state from SEMEDS for regions W, Mo-V-W and Cr-Mo-V-W as identified in Fig. 3a.

\begin{tabular}{ccccc}
\hline & $\mathrm{Cr}$ & $\mathrm{Mo}$ & $\mathrm{V}$ & $\mathrm{W}$ \\
\hline $\mathrm{W}$ & 0.0 & 0.0 & 0.0 & 100 \\
Mo-V-W & 0.0 & 37.2 & 35.9 & 26.9 \\
Cr-Mo-V-W & 31.3 & 23.6 & 26.4 & 18.7 \\
Dendrite & 14.9 & 27.8 & 19.5 & 37.8 \\
Interdendrite & 38.5 & 23.8 & 27.2 & 10.5 \\
\hline
\end{tabular}

Figure $3 \mathrm{c}$ shows TEM micrographs taken from dendrite and interdendritic regions of the CrMo-V-W phase. This is homogeneous on the submicron scale, with no evidence of spinodal decomposition and characteristic 'basket-weave' microstructure. The SAED pattern of the $\left[\begin{array}{lll}0 & 0 & 1\end{array}\right]$ zone axis, Fig. 3b, is consistent with a typical BCC crystal structure. No further features were identified by TEM.

Figure 4 shows the XRD pattern of the sample. The sharp peaks of the pure W were used as an internal calibration standard with the fixed lattice parameter $a_{0}=3.1648$ [72] to refine instrument parameters by Rietveld refinement. The Mo-V-W and Cr-Mo-V-W regions each have two sets of peaks attributed to their dendrite and interdendrite regions. Preferred orientation was evident in the 
peak intensities of the solid solutions. Le Bail fitting identified all phases as BCC with lattice parameters and microstrains stated in Table 3. A larger lattice microstain is observed in the Cr-Mo-VW phase from XRD pattern analysis compared with the other phases in Table 3, and is within the range of report values for BCC high-entropy alloys [73,74].

The predicted lattice parameter of CrMoVW SPHEA phase $(0.3053 \mathrm{~nm}$ from DFT) lies between the dendritic and interdendritic lattice parameter of respectively 0.3077 and $0.3008 \mathrm{~nm}$ of the Cr-MoV-W region. From measured composition and lattice parameters, their densities are 12.98 and 9.28 $\mathrm{g} / \mathrm{cm}^{3}$ and those of the ternary dendrite/interdendritic material 12.11 and $11.42 \mathrm{~g} / \mathrm{cm}^{3}$ (from the average composition). Therefore, in a backscattered electron image, the Cr-Mo-V-W dendrites are brighter than the Mo-V-W interdendritic material as in Fig. 3a.

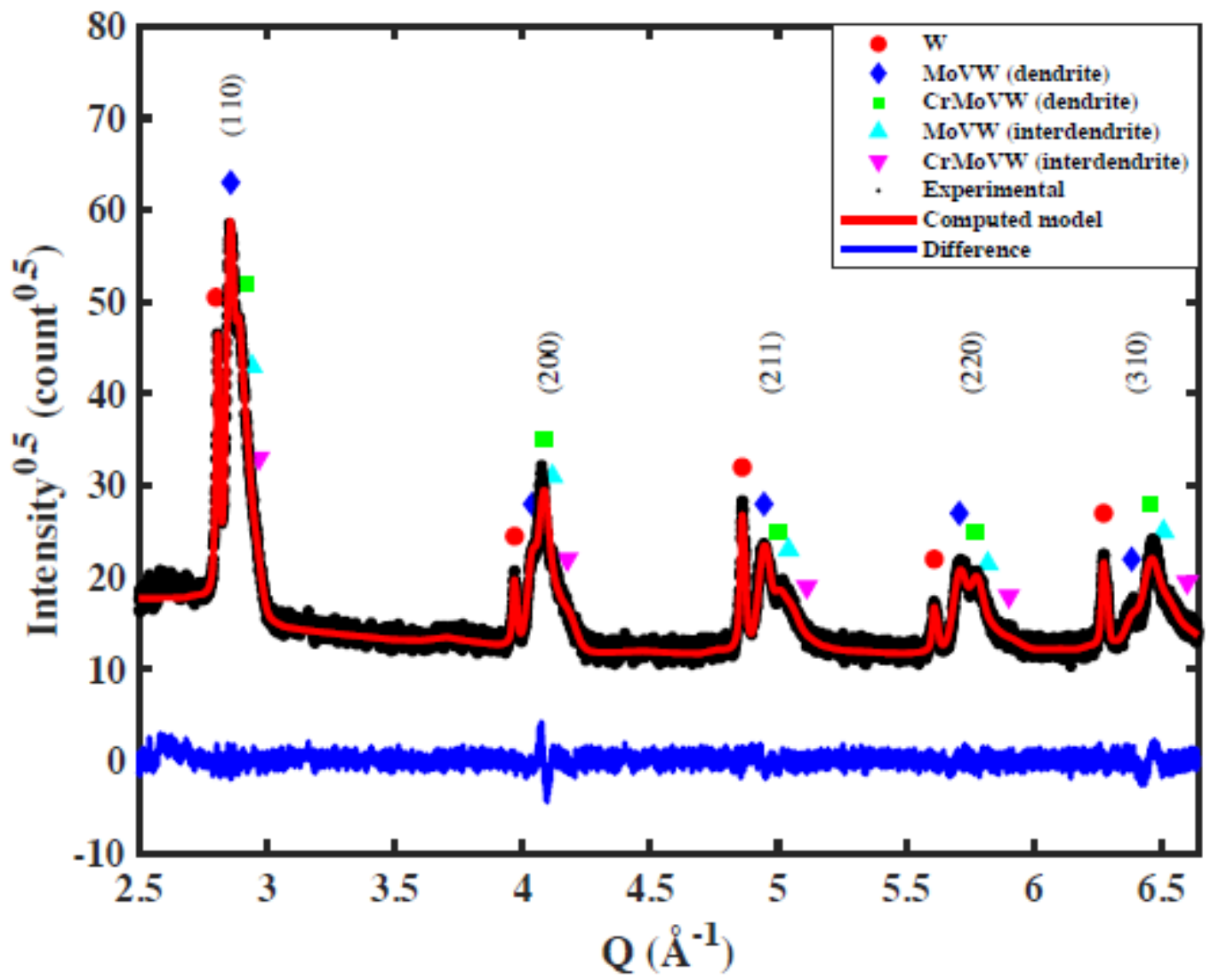

Fig. 4. X-Ray Diffraction pattern of as-cast CrMoVW with Le Bail fitting, showing observed pattern (black dot), computed model (red line) and the difference between observed and computed XRD pattern (blue line); peaks from dendritic and interdendritic regions are identified: W (red circle), $\mathrm{M}_{0}-\mathrm{V}-\mathrm{W}$ dendrite (blue diamond), $\mathrm{Cr}_{-} \mathrm{M}_{0}-\mathrm{V}-\mathrm{W}$ dendrite (green square), $\mathrm{Mo}_{0} \mathrm{~V}-\mathrm{W}$ interdendrite (cyan triangle) and $\mathrm{Cr}-\mathrm{M}_{0}-$ $\mathrm{V}-\mathrm{W}$ interdendrite (magenta triangle). 
Table 3. Crystallographic features of each phase of the as-cast high entropy alloy obtained from XRD diffraction analysis based on Le Bail fitting method.

\begin{tabular}{cccc}
\hline Phase & & Lattice parameter $(\mathrm{nm})$ & Microstrain (\%) \\
\hline \multirow{2}{*}{ Mo-V-W } & Dendrite & 0.3110 & 0.35 \\
& Interdendrite & 0.3050 & 0.59 \\
& Dendrite & 0.3077 & 0.35 \\
Cr-Mo-V-W & Interdendrite & 0.3008 & 0.65 \\
\hline
\end{tabular}

The lattice parameter of the SPHEA phase measured from the SAED pattern is $0.2967 \mathrm{~nm}$, smaller than the interdendritic lattice parameter from XRD results but within the precision of 2 to $3 \%$ for electron diffraction [68]. These considerations provide a consistent interpretation of the microstructure. Similar dendritic microsegregation is common in refractory HEAs e.g. MoNbTaW, NbHfTiZr and MoNbVW and annealing above $~ 1200 \mathrm{~K}$ can achieve a homogenous single phase from their dendritic as-cast structures $[69,70]$.

Although the casting of a homogenous alloy was limited by the melting process [71], it has been demonstrated by the last-solidified region and theoretical simulation, that a BCC, quaternary, SPHEA - CrMoVW - can form. Crucially, the theoretical methods and experiment are in agreement with one another, which lead to the conclusion that there is an extensive stable composition range of a BCC solid solution in this system. If the dendritic and interdendritic regions in the current sample can be homogenised, then the SPHEA of CrMoVW will be realisable experimentally. With its extremely high melting temperature, high $\mathrm{Cr}$ alloying and wide $\mathrm{BCC}$ composition space, the discovery of this new SPHEA system promises further developments and likely applications in high temperature, oxidising environments. 


\section{Acknowledgements}

Funding: the Taste of Research Scholarship, resources and facilities from School of Material

Science and Engineering and Mark Wainwright Analytical Centre, UNSW Sydney; computing infrastructure by EPSRC Tier 2 allocation on CSD3 (Skylake and KNL) HPCs, Australian National Computational Infrastructure (Raijin) and Imperial College Tier 2 (Cx1 and Cx2); TEM facilities at ANSTO Nuclear Materials Development and Characterisation Platform; charitable financial support of ANSTO and the Tyree Foundation. We thank Mr. Kim Lu for the preparation of TEM samples.

\section{References}

[1] J. Wu, S. Lin, J. Yeh, S. Chen, Y. Huang, H. Chen, Wear. (2006) 513-519.

[2] C.-M. Lin, H.-L. Tsai, Mater. Chem. Phys. 128 (2011) 50-56.

[3] M.A. Hemphill, T. Yuan, G.Y. Wang, J.W. Yeh, C.W. Tsai, A. Chuang, P.K. Liaw, Acta Mater. 60 (2012) 5723-5734.

[4] S.C. Middleburgh, D.M. King, G.R. Lumpkin, M. Cortie, L. Edwards, J. Alloys Compd. 599 (2014) 179-182.

[5] Y. Zhang, T.T. Zuo, Z. Tang, M.C. Gao, K.A. Dahmen, P.K. Liaw, Z.P. Lu, Prog. Mater. Sci. 61 (2014) $1-93$.

[6] B. Gludovatz, A. Hohenwarter, D. Catoor, E.H. Chang, E.P. George, R.O. Ritchie, Science (80-. ). 345 (2014) 1153-1158.

[7] J. W. Yeh, S. K. Chen, S. J. Lin, J. Y. Gan, T. S. Chin, T. T. Shun, C. H. Tsau, S. Y. Chang, Adv. Eng. Mater. 6 (2004) 299-303.

[8] B. Cantor, I.T.H. Chang, P. Knight, A.J.B. Vincent, Mater. Sci. Eng. A. 375-377 (2004) 213-218.

[9] Y.J. Zhou, Y. Zhang, Y.L. Wang, G.L. Chen, Mater. Sci. Eng. A. 454-455 (2007) 260-265.

[10] B.S. Li, Y.P. Wang, M.X. Ren, C. Yang, H.Z. Fu, Mater. Sci. Eng. A. 498 (2008) 482-486.

[11] Y.-L. Chen, Y.-H. Hu, C.-A. Hsieh, J.-W. Yeh, S.-K. Chen, J. Alloys Compd. 481 (2009) 768-775.

[12] Z. Wang, S. Guo, C.T. Liu, JOM. 66 (2014) 1966-1972.

[13] M.-R. Chen, S.-J. Lin, J.-W. Yeh, S.-K. Chen, Y.-S. Huang, C.-P. Tu, Mater. Trans. 47 (2006) 13951401.

[14] Y.J. Zhou, Y. Zhang, Y.L. Wang, G.L. Chen, Appl. Phys. Lett. 90 (2007) 181904.

[15] M.-H. Chuang, M.-H. Tsai, W.-R. Wang, S.-J. Lin, J.-W. Yeh, Acta Mater. 59 (2011) 6308-6317.

[16] K. Zhang, Z. Fu, Intermetallics. 22 (2012) 24-32.

[17] S. Guo, Q. Hu, C. Ng, C.T. Liu, Intermetallics. 41 (2013) 96-103.

[18] Y. Wang, S. Ma, X. Chen, J. Shi, Y. Zhang, J. Qiao, Acta Metall. Sin. (English Lett. 26 (2013) $277-284$

[19] Y. Yu, J. Wang, J. Li, H. Kou, W. Liu, Mater. Lett. 138 (2015) 78-80.

[20] J. Chen, P. Niu, Y. Liu, Y. Lu, X. Wang, Y. Peng, J. Liu, Mater. Des. 94 (2016) 39-44.

[21] T. Lindner, M. Löbel, T. Mehner, D. Dietrich, T. Lampke, Metals (Basel). 7 (2017).

[22] J.-M. Wu, S.-J. Lin, J.-W. Yeh, S.-K. Chen, Y.-S. Huang, H.-C. Chen, Wear. 261 (2006) 513-519.

[23] C. Li, J.C. Li, M. Zhao, Q. Jiang, J. Alloys Compd. 475 (2009) 752-757.

[24] Z. Hu, Y. Zhan, G. Zhang, J. She, C. Li, Mater. Des. 31 (2010) 1599-1602.

[25] Z.-C. Chang, S.-C. Liang, S. Han, Y.-K. Chen, F.-S. Shieu, Nucl. Instruments Methods Phys. Res. Sect. B Beam Interact. with Mater. Atoms. 268 (2010) 2504-2509.

[26] A. Cunliffe, J. Plummer, I. Figueroa, I. Todd, Intermetallics. 23 (2012) 204-207.

[27] X. Yang, Y. Zhang, Mater. Chem. Phys. 132 (2012) 233-238.

[28] M. REN, B. LI, H. FU, Trans. Nonferrous Met. Soc. China. 23 (2013) 991-995.

[29] D.J.M. King, S.C. Middleburgh, A.G. McGregor, M.B. Cortie, Acta Mater. 104 (2016) 172-179.

[30] F.R.D. Boer, Cohesion in Metals: Transition Metal Alloys. Elsevier, Amsterdam (1988).

[31] G.T.J. Mayo, W.H. Shepherd, A.G. Thomas, J. Less Common Met. 2 (1960) 223-232. 
[32] J.H. Perepezko, R. Sakidja, JOM. 62 (2010) 13-19.

[33] O.N. Senkov, C.F. Woodward, Mater. Sci. Eng. a-Structural Mater. Prop. Microstruct. Process. 529 (2011) 311-320.

[34] O.N. Senkov, S. V Senkova, D.M. Dimiduk, C. Woodward, D.B. Miracle, J. Mater. Sci. 47 (2012) 6522-6534.

[35] O.N. Senkov, S. V Senkova, C. Woodward, D.B. Miracle, Acta Mater. 61 (2013) 1545-1557.

[36] O.N. Senkov, S. V Senkova, C. Woodward, Acta Mater. 68 (2014) 214-228.

[37] O.N. Senkov, C. Woodward, D.B. Miracle, JOM. 66 (2014) 2030-2042.

[38] B. Zhang, M.C. Gao, Y. Zhang, S.M. Guo, Calphad. 51 (2015) 193-201.

[39] D. Schliephake, C. Gombola, A. Kauffmann, M. Heilmaier, J.H. Perepezko, Oxid. Met. 88 (2017) 267277.

[40] P. Lu, J.E. Saal, G.B. Olson, T. Li, O.J. Swanson, G.S. Frankel, A.Y. Gerard, K.F. Quiambao, J.R. Scully, Scr. Mater. 153 (2018) 19-22.

[41] D.J.M. King, University of Technology Sydney, (2016).

[42] D.M. King, S.C. Middleburgh, L. Edwards, G.R. Lumpkin, M. Cortie, JOM. 67 (2015) 2375-2380.

[43] S. Fang, X. Xiao, L. Xia, W. Li, Y. Dong, J. Non. Cryst. Solids. 321 (2003) 120-125.

[44] F. Tian, L.K. Varga, L. Vitos, Intermetallics. 83 (2017) 9-16.

[45] A. Calvo, C. García-Rosales, F. Koch, N. Ordás, I. Iturriza, H. Greuner, G. Pintsuk, C. Sarbu, Nucl. Mater. Energy. 9 (2016) 422-429.

[46] J.-O. Andersson, N. Lange, Metall. Trans. A. 19 (1988) 1385-1394.

[47] K.B. Zhang, Z.Y. Fu, J.Y. Zhang, J. Shi, W.M. Wang, H. Wang, Y.C. Wang, Q.J. Zhang, J. Alloys Compd. 502 (2010) 295-299.

[48] L. Jiang, Y. Lu, Y. Dong, T. Wang, Z. Cao, T. Li, Intermetallics. 44 (2014) 37-43.

[49] A.K. Singh, A. Subramaniam, J. Alloys Compd. 587 (2014) 113-119.

[50] Z. Wu, H. Bei, F. Otto, G.M. Pharr, E.P. George, Intermetallics. 46 (2014) 131-140.

[51] F. He, Z. Wang, Q. Wu, J. Li, J. Wang, C.T. Liu, Scr. Mater. 126 (2017) 15-19.

[52] M.G. Poletti, G. Fiore, F. Gili, D. Mangherini, L. Battezzati, Mater. Des. 115 (2017) 247-254.

[53] K. Zhang, Z. Fu, Intermetallics. (2012) 24-32.

[54] M. Gao, D. Alman, Entropy. 15 (2013) 4504-4519.

[55] F. Zhang, C. Zhang, S.L. Chen, J. Zhu, W.S. Cao, U.R. Kattner, Calphad-Computer Coupling Phase Diagrams Thermochem. 45 (2014) 1-10.

[56] B. Module, T. Module, P. Models, C.U. Tchea, (2015) TCHEA2: TCS High Entropy Alloy Database v2.1, Thermo-Calc Software AB..

[57] D.B. Miracle, O.N. Senkov, Acta Mater. 122 (2017) 448-511.

[58] C. Zhang, F. Zhang, S.L. Chen, W.S. Cao, J. Miner. Met. Mater. Soc. 64 (2012) 839-845.

[59] D.J.M. King, P.A. Burr, E.G. Obbard, S.C. Middleburgh, J. Nucl. Mater. 488 (2017) 70-74.

[60] P. Lipetzky, JOM. 54 (2002) 47-49.

[61] W. Takahara, IOP Conf. Ser. Mater. Sci. Eng. 61 (2014) 12029.

[62] A. Van de Walle, P. Tiwary, M. De Jong, D.L. Olmsted, M. Asta, A. Dick, D. Shin, Y. Wang, L.-Q. Chen, Z.-K. Liu, Calphad. 42 (2013) 13-18.

[63] C. Niu, A.J. Zaddach, A.A. Oni, X. Sang, J.W. Hurt, J.M. LeBeau, C.C. Koch, D.L. Irving, Appl. Phys. Lett. 106 (2015) 161906.

[64] L. Lutterotti, H. Wenk, S. Matthies, in: ICOTOM 12, NRC Research Press, 1999: pp. 1599-1604.

[65] G.R. Holcomb, J. Tylczak, C. Carney, JOM. 67 (2015) 2326-2339.

[66] O.N. Senkov, G.B. Wilks, D.B. Miracle, C.P. Chuang, P.K. Liaw, Intermetallics, 18 (2010) 1758-1765.

[67] B. Gorr, M. Azim, H.-J. Christ, H. Chen, D.V. Szabo, A. Kauffmann, M. Heilmaier, Metall. Mater. Trans. A. 47 (2016) 961-970.

[68] D.B. Williams, C.B. Carter, Transmission Electron Microscopy: A Textbook for Materials Science, Kluwer Academic Pub, 1996.

[69] Y. Zou, S. Maiti, W. Steurer, R. Spolenak, Acta Mater. 65 (2014) 85-97.

[70] Y.D. Wu, Y.H. Cai, T. Wang, J.J. Si, J. Zhu, Y.D. Wang, X.D. Hui, Mater. Lett. 130 (2014) $277-280$. [71] Y. Zhang, S.G. Ma, J.W. Qiao, Metall. Mater. Trans. A. 43 (2012) 2625-2630.

[72] L.S. Dubrovinsky, S.K. Saxena, Phys. Chem. Miner. 24 (1997) 547-550.

[73] Z. Fu, W. Chen, S. Fang, D. Zhang, H. Xiao, D. Zhu, J. Alloys Compd. (2013) 316-323.

[74] B.R. Braeckman, D. Depla, J. Alloys Compd. 646 (2015) 810-815. 